\section{ORIGHTAT COMI.MUTHCATIOHS.}

\section{INVERSION OF THE UTERU'S AFTER PAR- TURITION, FATAL IN SIXTEEN WEEKS; WITH REMARKS.}

By F. W. MACKENZIE, M.D.Lond., Physician to the Paddiugton Free Dispensary for Diseases of Women and Children.

Fraxces Gripritus, aged 26, married three years, of short stature, but well proportioned, was admitted into the Paddington Infirmary, December 15th, 1852. She was suffering from anæmia in an intense degree. From her history, it appeared that it had followed a confinement, which had taken place rather more than two months previous to her admission. This had been attended by an unusual amount of himorrhage, which had frequently recurred subsequently; and her husband being out of work, she had since been in a very destitute state, and obliged to undergo much physical fatigue. On admission, the hamorrhage had ceased; and, as she neither complained of any uterine symptoms, nor stated anything which led to a suspicion that any particular lesion had occurred during labour, no immediate examination of the uterus was made. She was ordered to be kept perfectly quiet in the recumbent position, and to have a light nutritive diet; and the mineral acids were prescribed, with occasional mild aperients. For three weeks, she continued progressively to improve, scarcely any homorrhage occurring during this period. She gained strength and colour: and the only altcration made in the treatment consisted in the addition to each dose of the mineral acids of ten minims, increased to fifteen, of the muriated tincture of iron.

Her favourable progress continued until January 4th, 1853, when menstruation began. This commenced normally, without pain, and without being excessive; but, in anticipution of its becoming profuse, she was ordered to take gallic acid in five grain doses every four hours. Everything went on favourably until the $6 \mathrm{th}$, when a profuse and unexpected loss of blood took place.

In my absence, she was seen by Mr. Norway, who, finding her blanched and nearly pulseless, ordered her stimulants, and directed the dose of gallic acid to be increased from five to ten grains. In the course of the day, she had somewhat rallied; and, on visiting her, I directed the same treatment to be continued, with some unimportant additions. The next day, the hæmorrhage had considerably lessened. On the 19th, it returned, and screral large coagula passed. After this, it again lessened, and on the 22nd she was removed to the lying-in ward, where an cxamination of the uterus was made.

On introducing the finger into the vagina, a somewhat elongated pyriform tumour was found to occupy the upper part of this organ. It was about the size of an egg, was firm and somewhat clastic to the touch, and its surface had a fine velvety character. On tracing it upwards, it became somewhat narrower, and was at length felt to be embraced by the uterus, which completely encircled it. Inferiorly, its transverse diameter might be about an inch and a half; superiorly, it was somewhat less. It was smaller in its antero-posterior than in its transverse diameter, and in length might be about two inches. On pressing it with the pulp of the finger, the patient stated that she felt no particular pain; and, as far as could be judged from repeated trials, the tumour was not very sensible to this kind of pressure. On introducing a speculum very cautiously, the surface of the tumour was found to be covered with a layer of coagulated blood, which gave it a dark purplish appearance. On wiping this away, a convex body was brought into view, of a pale red or salmon colour, and, on touehing it with the blunt end of a probe, pain was distinctly felt; whilst, from the several points of the tumour touched, fine capillary streams of blood poured forth. There could thus be no doubt that the tumour was an inverted uterus; and, on inquiring more particularly into the histary of the case, the following particulars were elicited.

The patient had been married nearly throe years, and had given birth to two children. The first was born on the 11th of February, 1851, about ten months after marriage; the second, on the 11th of October, 1852. The first labour was long and difficult; and the child, though born alive, died two days afterwards. The placents was retained, and had to be separated manually from the uterus. She, however, did well, and recovered without any unfarourable symptom. Menstruation returned in due course, and she neither experienced any uterine pain nor leucorrhoea subsequently to this lalour. In the beginning of January 1852, she again became pregnant, and went the full period of gestation without any unfarourable symptom. She was confined on the 11th of December, 1852. The labour was easy and expeditious, as far as the birth of the child was concerned. With regard to the placenta, the gentleman who attended her informs me that, in this labour, it was not adherent, and that it camc away at the usual time, by simply pulling moderately, and without any force, upon the cord. After its removal, he made an examination of the uterus, and felt something protruding into the vagiua, which he suspected to be an inverted uterus. He accordingly made several attempts to replace it, and after a time was led to believe that he had succeeded in doing so. These attempts, however, the patient appears to have considered to have been made for the purpose of removing the placenta; for she stated that it was adherent; that, half an hour after the birth of the child, an attempt was made to remove it, which failed; and that it was not brought away until an hour and a half after the child had been born. Soon after its supposed removal, she stated that she experienced, in the uterus, intense pain of a burning character, which was attended with profuse hæmorrhage. The pain was so severe, that it occasioned her to be delirious; and, although it was somewhat allayed by the remedies employed, it nevertheless continued for three days, with occasional intermissions, in a very severe form. The day after her confinement, she was visited by her medical attendant and another practitioner; and the lattcr attempted, she stated, some manipulations, but failed to give any relief. Matters thus continued for five days longer, when another consultation was held upon her case, and a third medical man attempted, but unsuccessfully, the reduction of the uterus. From this time, she continued to suffer more or less from uterine hxmorrhage for some weeks, and her stomach became so irritable, that she could scarcely retain any food. Under the treatment adopted, however, she eventually improved; and, as previously stated, on her admission into the infirmary, the hacmorrhage had ceased.

From the 22nd to the 27 th of January, there was scarcely any return of hæmorrhage. The bowels had been regulated by castor oil ; but, on account of the irritability of stomach, and the expressed wish of the patient, no other medicine was given. Her diet was light and nutritive, and she was allowed $6 \mathrm{oz}$. of port wine daily.

On the night of the $26 \mathrm{th}$, she was seized with faintness, and profuse hæmorrhage again took place. This was attributed by the nurse to her having fretted about her child, who had been attacked with hooping-cough the preceding day. Gallic acid was again ordered in ten grain doses every four hours; and pledgets of lint, soaked in alum water, were applied to the uterus. As, however, it became evident that these hæmorrhages could not be prevented, and as it was equally certain that she would sink under their continuance, I determined to take steps for the removal of the inverted portion of the uterus.

On the 28th, the hæmorrhage had almost entirely ceased, and she was visited by Mr. Marshall, to whom I had communicated my intention of remoring the inverted portion of the uterus by the electric cautery. He thought favourably of the operation, and I accordingly gave directions for the preparation of the necessary apparatus. In the mean time, the gallic acid was ordered to be continued, as well as the application of the solution of alum to the fundus uteri. 
The propriety of attempting the forcible reduction of the the proph chloroform was considered on this and other uterus under chloroform was consider the grounds, l, that attempts had already been made at an earlier and consequently tempts had alreace period, and had failed; 2 , that the attempt had almost always been unsuccessful, when made at such a late period after the accident; and 3 , that, if it were attempted without success, considerable injury might be done the patient in her then exhausted condition. I was not then aware that reduction had been effected under chloroform at an equally latc period, or the attempt would cer tainly have been made.

January 29th. No particular hacmorrhage had occurred; but a large quantity of serous fluid was passing from the vagina; the countenance was extremely exsanguine, and the bowels were flatulent and confined. The patient was directed to take twenty drops of oleum terebinthina erery four hours, in addition to the gallic acid.

January 30th. She was still suffering from a profuse serous discharge, and was excessively weak and ancemic. The face was stvollen and nedematous, especially under the cyes, and she felt a disinclination to take food. The turpentine was not given on account of her excessive objection to it. She was ordered to have four ounces of brandy daily, in addition to six ounces of port wine, three eggs, beef-tea, and arrow-root. The gallic acid was continued; and, if restless or sleepless at night, she was to take ten drops of laudanum erery half-hour, until sleep or quietude were olbtained.

January 31st. She harl passel a comfortable night, and felt somewhat hetter, although no opiate was given. 'There had heen sciarcely any hiemorrhage; and the serous discharge from the vagina had very much leseened. Twenty drope of dilute nitro-muriatic acid were now ordered to be taken in water with each dose of the gallic acid.

February 1st. No hæmorrhage had yet returned; but a serous fluid still passed from the ragina. She was extremely prostrate and exsanguine; and her stomach was 80 irritable that she could with difficulty retain the gallic acid pills. They were accordingly discontinued, and she was pills. They were accordingly discontinued, and she was with an opiate at night if restless.

February 3rd. There had been no return of hæmorrhage; and the colourless discharge was now very slight; but the cxpression of the patient was one of extreme prostration, and her breathing was laboured and at times difficult. Hex and her breathing was now so irritable, that she took food with reluctance. She was ordered to continue the dilute nitromuriatic acid in water, and to take with each dose ten minims of tincture of opium. The symptoms of exhoustion continued to increase throughout the day, and she died at half-past elcven, P.M.

Post Mortey Fxamixatiox, made on 5th February. No abnormal appearances were met with, beyond those connected with the uterus, and the exsanguine state of the system to which it had given rise. The condition of the uterus is well shown in the accompanying woodcut, and thercfore little need be added in explanation. It will be therefortions of the fundus uteri to the cervix and vagina, and the entrance of the round ligaments and Fallopian tubes into the pcritoneal col de sac of the fundus are very clearly shown, as well as the form, size, and general characters of the inverted portion of the uterus.

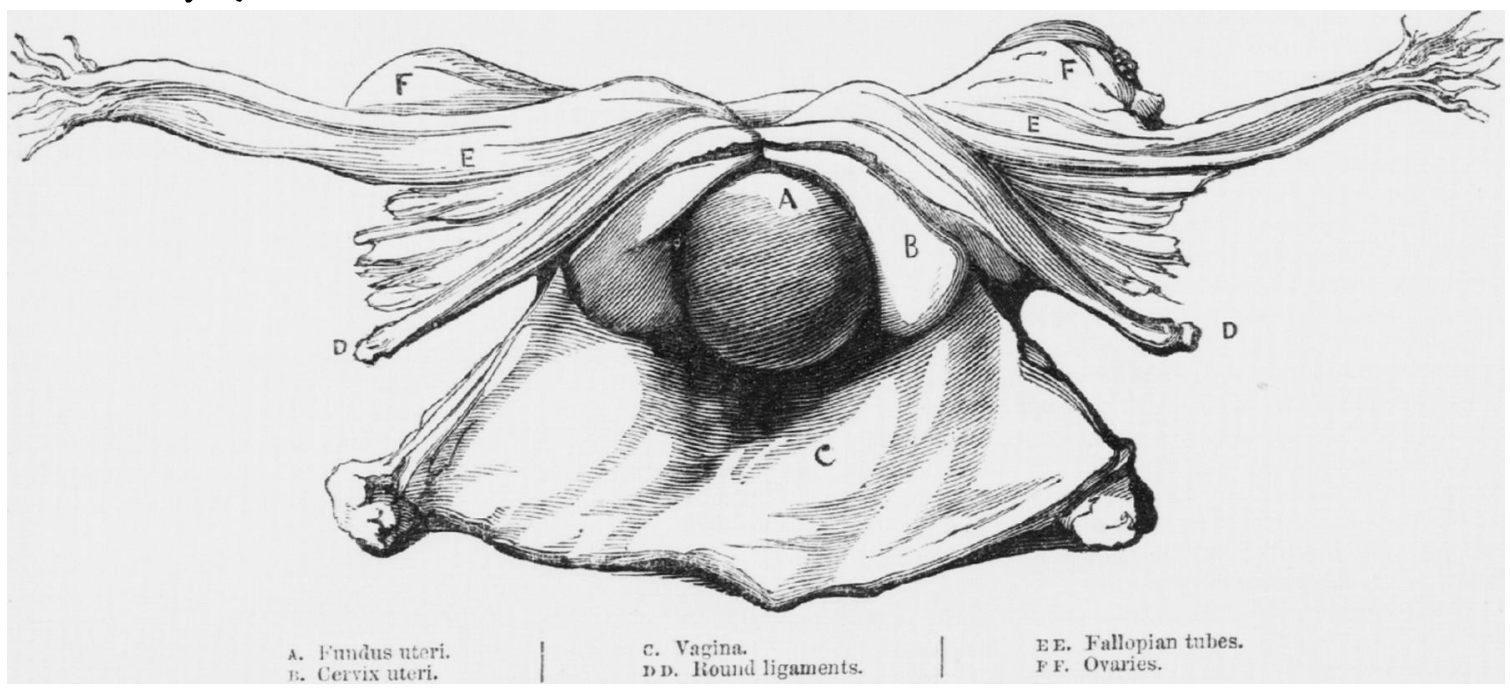

Rruskis. In revicwing the circumstances of this melancholy case, I will contine myself to a brief consideration of some of the more practical questions which arise in connexion with the causes, consequences, and treatment of inversion of the uterus.

Cavses. At the present day, a difference of opinion appears to cxist as to the nature of the causes which give rise to this displacement, in connexion with parturition. By sone writers it is regarded as the consequence of improper mechanical interference or traction upon the cord: whilst by others it is supposed to occur independently of any such causes, and to be the consequence solely of a preternatural or perverted action of the uterus. I believe, however, that a careful consideration of the facts of various recorded cases will terid to shew that neither of these extreme views is correct ; and that, whilst in a large number of cases it has been immediately occasioned by improper interference, in others it has occurred spontaneously, or at least in the absence of any such causc. Smellie, for instance, relates a case in which it was occasioned "by the midwife's pulling at the placenta with too great force." (Cases in Miduifery, vol. iii, p. 494.) Mauriceau gives a case which was occasioned by "violent extraction of the placenta," and was followed by hæmorrhage during a period of eight months. (Tom. ii, obs. 355, p. 294.) Gifford reports a case, in which " the midwife, in attempting to bring away the placenta, inverted the uterus." (Cases in Midroifery, p. 421.) Chapman relates a case, of which the midwife told him "that the afterbirth stuck so fast in one part that she was not able, with all her strength, to take it from her, though she had gained the most of it." Upon this, the patient having died, he desired to see the corpse, and found, to his great surprise, "that the uterus was inverted, and entirely out of the body, with the placenta adhering to its fundus. The patient," he adds, "had a very good and easy delivery of the child; but that born, the midwife pulled hard at the string and so brought down the uter us, which 
as soon as she could take hold of ahe did, and then pulling with fresh violence, and not being deterred by the loud cries of the poor miserable woman, who, in a few minutes, fell into strong convulsions and deliquia, and so expired." Perfect relates two cases of inversion, which were caused by improper mechanical interference. In the first, the midwife, "after waiting some time in expectation of the secundines, was at length induced to pull with very great force at the funis, by which the accident was occasioned." In the second, "the patient had a serere labour of three days and nights, and lost her life by the hasty and violent manner in which the midwife pulled at the funis, and by which means an entire inversion of the womb was brought on." (Cases in Midvoifery, vol. ii, pp. 6-9.) Mr. Barker reports a case which was occasioned from the interference on the part of a midwife. "At the end of half an hour after the birth of the child the placenta had not separated, and she accordingly proceeded to remove it, in doing which she employed so much force that she dragged out the after hirth and uterus together." (Med. Phys. Journ., vol. xxv, p. 210.) Other cases might be quoted to show that this accident has evidently arisen solely and entirely from undue traction upon the cord or some improper interference in the management of the placenta.

On the other hand, well authenticated cases may be adduced to show that inversion of the uterus has occurred spontaneously, or at least in the absence of any mechanical interference. Dr. Humphreys Storrer relates the following. "He was called to a woman in labour. In ten or fifteen minutes there came two smart pains, and the child was born. In five minutes the placenta was thrown off. The cord was not touched, except to divide it and remore the child. On putting his hand under the clothes, to take a way, as he supposed, the placenta, he found that he had hold of the placenta with the uterus attached." (Medical Gicustte, December 1842, p. 428.)

Two cases of spontaneous inversion of the uterus are referred to by Dr. Mitchell, in the Dublin Merlical Press for September 23rd, 1846. The first occurred in the practice of Dr.Ashwell, who states, "that it was entirely spontaneous ; for a friend, who was present during the labour, assured him that the midwife did not touch the cord. The child was expelled very quickly, and the patient felt a sudden pain, and said that something else was coming. On examination, Dr. A. found the uterus completely inverted, with the placenta adherent." In the sccond case, quoted from Dr. Lever, " the patient was delivered after a quick labour of a living child. In a few minutes, without any traction upon the cord, the patient complained of sudden pain, and said that something more had been expelled. The surgeon immediately passed his hand above the pubes, but could not detect the womb; and an attempt to make a vaginal examination satisfied him that the uterus was completely inverted." Mr. Clarkson reports the following. " $\mathrm{He}$ was called to a lady, aged 34 , a short stout woman, then in labour of her eleventh child. He found her walking about the house apparently very comfortable, having had but few pains, and those at long intervals, during the day. Her former labours had been quick. On examination per vagivam, the head was found low down in the cavity of the pelvis, and the labia and perineum soft and dilatable. As yet, there had been no uterine contraction since he had entered the room ; but just as she was getting off the bed, in order that it might be more comfortably prepared, a violent pain came on, and almost before he could apply his hand to the perineum the child was expelled, and the placenta brought to the os externum by the continuance of the same pain. Having hastily tied and divided the funis, and removed the placenta, which was perfectly loose, he found, on examination, that the uterus was partially inverted." (Lancet, vol. ii, p. 406.)

In the case I have related, I am informed by the gentleman who attended, that no undue traction was made upon the cord, that the placenta came away with ease, and that until he made a raginal examination he had no reason to suspect that the uterus had become inverted. I think it impossible to conclude from these facts otherwise than that inversion of the uterus may be both spoutaneous and the result of improper mechanical interference; and from a knowledge of this circumstance, we may learn, not only the necessity of extreme caution in the management of the placenta, but also the possibility of inversion occurring even where no violence has been used.*

Symptoxs axd Diagnosis. The symptoms of inversion vary very considerably in different cases, and in all are materially modified by the extent or degree of the displacement. When complete, the symptoms are for the most part of a marked and severe character. The constitution is profoundly impressed, and the immediate consequences are, in the words of Mr. Newnham, "hæmorrhage more or less considerable, accompaniod with pain and expulsive efforts, and rapidly followed by syncope, convulsions, nausea, vomiting, hiccup, and sometimes death". When, on the other hand, the inversion is partial or incomplete, the character of the symptoms will mainly depend upon the extent of the displacement. In simple depression there may be little more than hremorrhage, and an unusual prostration of the constitutional powers. In introversion, in addition to increased constitutional disturbance, as indicated by pallor, clammy skin, feeble pulse, and other symptoms of nervous depression, there is usually inordinate hremorrhage accompanied by fulness, weight, uneasiness in the vagina, and coustant expulsive efforts. In perversion the local and constitutional symptoms are of a still more aggravated character. There is great distress, alarming restlessuess, clammy perspirations, cold extremities, a rapid feeble pulse, vomiting, with, in some cases, convulsions, delirium, and syncope. In the case I have reported, there was profuse hamorrhage and uterine pain of such an agonising character as to render the patient delirious. I do not, however, feel it necessary to dwell at greater length upon this part of the subject, but will content myself with observing that, when in connexion with a rapid labour or any difficulty in the extraction of the placenta, a patient is attacked with either syncope, restlessness, hæimorrhage, inordinate uterine pain, or expulsive efforts, the possibility of the existence of inversion should be suspected, and a careful examination made of the hypogastrium, and of the uterus per vaginam and per rectum, which will incvitably lead to its discovery, if present.

In the chronic stage, inversion of the utcrus may be confounded with either prolapsus or polypus. From the former, its diagnosis is comparatively easy ; from the latter, more difficult. Much stress has been laid upon the sensibility of an inverted uterus on the one hand, and the insensibility of a polypus on the other; but this ground of diagnosis, so far as it rests upon mere tactile examinatiou, appears to me to be of a very doubtful character. In the case which $I$ have recorded, the sensibility of the uterus to the pressure of the finger was extremely questionable, and repeated trials left me uncertain as to whether any distinct pain was occasioned by pressure or not. I would suggest that the fact of the inverted portion of the uterus being in a state of strangulation, from the constriction of the surrounding cervis, must very materially modify, if not in many cases completely annihilate, its sensibility; and that a better test of the character of the tumour would be the cautious introduction of the speculum. This, at least, was attended with considerable adrantage in the case $I$ have recorded. As distinguished from a polypus, which was ob-

- It forms no part of the object of this paper to inquire into the mechanism of mversion; but in using the term spuntuneous, I may be permitted to observe that it is intended to apply to chses which lave oceurred in the proare'ss of habour, independently of any artificial assistance. In such, doubtless, the causes which tend to the displacement are of a complex character. and require not only that the placenta should he attuched to the fundus uteri, but also that some undue pressure should be made externally upon this part of the organ, or some traction upon the funis lelow. This latur may occnr, in the unassisted birth of the child, eiller frorn the funis being preteruaturally short, or shortened by heing coiled round some part of the child, or by the child being expelled with great force or othervise, so as to produce a strain upon the cord. Inversion, thus commenced, will clubbtess pre increased and completed by the action of the ut:rus; but, being throughout inden dent of any extrancous force or assistance, nuay fairly be regurded as spoutaneous, although both physical and vital causes co-operate and are necessary for ite production. 
serred by Dr. Gooch to be of a pale flesh colour, mottled, or rather streaked with large blue veins, the inverted uterus was found to present an] uniform pale red or salmon colour; and on touching it with the blunt end of a probe, not only was pain distinctly felt, but fine capillary streams of blood were seen to issue from the several points of the tumour touched by the instrument.

Progress ayd Terminations. The progress and termination of inversion of the uterus, when uninterfered with by art, is well illustrated in the case I have related and it is more especially instructive, as showing not only how sudden and profuse are the hæmorrhages to which it may give rise, but also how little amenable they are to remedial measures, and consequently how uncertain is the tenurc of life under such circumstances. Reverting to the occurrence of homorrhage in this case, it would appear that, for some weeks after labour, it had been more or less persistent and profuse. At the end of two months it had entirely ceased, and under the treatment adopted in the infirmary did not recur for three weeks. Then came a menstrual period, which for four days appeared to be normal; then followed a sudden and profuse loss of blood, so considerable as to endanger her life. Then came a cessation, followed again hy hemorrhage, eyually profuse; and when red blood had ceased to flow, a drain of colourless fluid continued to escape from the inverted uterine surface, until the constitution of the patient was undermined and her vitality exhausted. With regard to the danger and fatality of inversion of the uterus, Mr. Crosse, in his memoir on the subject, states that, upon by fiur the most extensive data that hare yet been furnished, he is prepared to affirm that above onethird, under whatever circumstances, or in whatever degree it may occur, prove fatal either very soon or within one month after its occurrence. Of one hundred and nine fatal post pertum cases, collectel from various authenticated sources, he found that serenty two, or two-thirds, proved fatal within a few hours after dclivery, and most of them within half an hour or an hour. Eight proved fatal in from one to seren days; six in from one to four weeks; one in from four to five months. Of the remaining twenty-two, twelve proved fatal at the following periods; one at eight months, three at nine, one at twelre, two at twenty-two, one at two years, one at three, two at four, and one at five.

Treatur.xt. Such being the natural course and tendency of inversion of the uterus, we have in the last place to consider what means can be alopted for its cure or mitigation. And first, it may be observed that all writers are agreed as to the extreme importance of promptly recognising it when present and immediately attempting its reduction; for the delay of even a few hours has sometimes rendered this impossible. Dr. lenman found it impossible to replace the organ after a lapse of four hours. Dr. Merriman was called to a case but a few hours after the accillent had happened, and was unable to reduce it. Mr. Nelson relates a case, where reduction was impossible half an hour only after the inversion had taken place; and in the case $I$ have reported, attempts were made to replace the uterus on the first and sixth days after delivery without the least success. The general experience, moreover, of the most eminent obstetricians, supports the observation that the most favourable period for effecting a reduction is that which immediately succeds its occurrence.

But, at the same time, it may be obserred, that cases are recorded in which the attempt was successfully made many days and weoks after the accident had occurred; and I am more particularly anxious to direct attention to the advantages likely to be derived from the induction of anasthesia, when any difficulty arises in the reduction of the organ. I am the more led to do so, because I was not myself aware that this practice had been successfully adopted when the case I have reported was under treatment; and because, on suggesting it to various professional friends who visited the patient with me, I found that they were decidedly opposed to it, as being altogether futile. The following reference to cases where reduction was effected under anæsthesia, at lengthened periods after the accident had happened, may therefore prove useful, and serve to induce a trial of it in others.

M. Valentin reports the following :-On the 8th of April, 1846 , a female, aged 20 , of good constitution, was delivered of her first child. Inversion followed, and was attended by leucorrhoea and syncope. The former continued during an entire month, and was then replaced by a persistent hrmorrhage. On the 15th of August, 1847, the reduction was attempted; but the screams of the patient caused the operation to be abandoned. On the 26th, another attempt was made with the aid of ether inhalation. The patient being rendered insensible, the same manipulations were gone through; but, as before, the uterus was altered in form, without the fundus yielding as was wished. The attempt was persisted in for ten minutes without progress, when etherisation was carried to the extent of relaxation of when etherisation was carried to the extlapse of the system was complete; and the uterus partaking of the relaxation, the fundus allowed itself to be depressed under the finger, until it at length became suddenly restored to its normal state. In order to assure himself that the reduction was complete, the operator introduced his finger into the uterine cavity. (Revue Médico-Chirurg., Nov. 1847.)

Dr. Merriman quotes a case in which reduction was succcssfully performed, long after its occurrence, by M. Barrier, at tyons. The operation is thus described. The patient being placed on her back, the hips brought to the edge of the bed, the thighs scparated, and etherisation effected, M. Barrier introduced his hand into the vagina. To vive the uterus as much fixedness as possible, he placed it in the hollow of his four fingers ; then, by pressing with the ball of the thumb applied directly to the fundus uterithe most dependent part-he pushed it back in the direction of the axis of the outlet, with the intention of placing the neck of the uterus against the sacrum, and of supporting the extremity of the vagina by a resisting medium, in order to guard against its rupture. After a fer minutes of gentle but sustained pressure, the fundus uteri had entered into itself from two to three centimetres. The same pressure was still kept up for an instant, when, feeling the organ gradually give way, the operator passed his index and ring fingers into the depression, where his thumb had begun to lodge itself, as he pressed back the fundus uteri. With these two fingers, he changed the direction of the force, without increasing its amount; he then pushed back the fundus uteri from below upwards, and from before backwards. Immediately the uterus yiclded completely, and took again its natural position. (Med. Times and C'azette, Sept. 4th, 1852.)

Mr. Canney publishes a case of chronic inversion, in which reduction was successfully performed some months after the occurrence of the accident, under the following circumstances. The patient was laid on her right side diagonally across the bed, the nates projecting over the edge of the bed, and the knees being well drawn up, chloroform was administered to the extent of producing complete relaxation of the sphincters. The fingers of the right hand, formed into a cone, were now applied to the os externum; and, as soon as the chloroform had been inhaled for a short time, the entire hand passed almost without resistance into the vagina. The tumour was now grasped between the fore and ring fingers; it was supported in front by the thumb, and the point of the middle finger was applied to the apex of the tumour: the hand, with the wrist extended, was carried up, until the vagina was put fully on the stretch; and then, by slightly flexing the wrist, the tumour was gently pushed forwards and upwards, in the direction of the axis of the brim of the pelvis. As soon as the patient came under the full anæsthetic influence of chloroform, the tumour gradually receded, and the inversion was successfully reduced; the whole operation, from the first inhalation of chloroform, not occupying more than five or six minutes, and the force used being almost trifling. (Med.Times and Gazette, Sept. 18th, 1852.)

In a fourth case, Dr. Ayer succeeded in reducing an in- 
version, thirt hours after it had taken place. He observes, "Having reflected on the relaxing effects of ether on the tissues, I determined to give it a trial, and, accordingly, while the inhalation was gradually conducted by an assistant, I grasped the fundus uteri, and made gentle pressure. As the system became relaxed, the tumour gradually diminished. In thirty minutes, the vulva became perfectly flabby, and the tumour soft and compressible. I made firmer pressure, and it was reduced to the size of a hen's egg; the finger could circumscribe it. It remained from twenty to thirty minutes of this size, uncertain whether further ground could be gained, and then disappeared per saltum, with the peculiar feel of a receding hernial tumour." (Canada Med. Jour., July 1852.)

The success attending the reduction of the uterus in these cases, in a state of anresthesia, appears to have been of an unequivocal character, and such as to justify our having recourse to it in others, before deciding upon the impracticability of reducing the organ.

But, should such attempts fail, and the patient's life be endangered by hæmorrhages or other exhausting discharges, we have then to consider the propriety of removing the inverted portion of the uterus. For this purpose, two methods hare been employed, viz., excision and ligature; but the results of neither, it must be added, have been of a very encouraging character. The dangers attending excision are so great, that we are told, with reference to a case in which it was successfully performed by Velpeau, that the jeopardy of the patient was such, that it will doubtless not be often repeated; and, with regard to ligature, although many successful cases are reported, there is yet a formidable array of others in which it has proved fatal. Under these circumstances, I was led to belicve that the electric cautery might be more successfully employed for the extirpation of the organ; and in this opinion I was supported by Mr. Marshall, who, after visiting and examining the case, expressed himself favourably of the operation. Unfortunately, unforeseen difficulties arose in the preparation of the necessary instruments; and, beforc their completion, the patient had sunk under the influence of sudden and profuse losses of blood. As, however, these difficulties have now been overcome, I will, before concluding, describe the nature of the apparatus by which the operation was proposed to be performed.

The battery intended to be used was necessarily one of considerable power; and to its terminal poles a modification of Gooch's canula instrument for the removal of uterine polypi was to be affixed. As now completed, this consists of two rods, one of which is solid, the other hollow, and covered with a wove flax surface, coated with solution, to insulate the platinum wire or chain which passes through it. One end of this wire or chain, of proper thickness, is soldered to the extremity of the solid rud; the other, having passed through the interior of the tubular one, is attached to a rack and windlass, affixed to the lower part of it. In using the instrument, the two rods are introduced together parallel to each other, and, having reached the ncck of the inverted portion of the uterus, are then separated, and passed round it, as in the ordinary operation for removing a polypus: their upper extremities are fixed together by means of a silver sliding rod, having rings at its superior extremity. The platinum wire having been now tightened by means of the rack and windlass, the two rods are respectively affixed to the poles of the battery; and the platinum wire being heated by closing the circuit of electricity, it is gradually tightened by turning the windlass until the division of the organ is accomplished.* I am unable to speak from experience of the practical working of this contrivance; but I am disposed to think that it, or some modification of it, may be usefully employed for the operation in question.

Reviewing, then, the chief circumstances of the case I have reported, I would more particularly wish to direct

- The apparatus in question has been constructed by Mr. Coxeter, who wil] give any further information that may be required respecting $j$. attention to the importance of the following consider ations:-

1st. A due appreciation of the circumstances under which inversion of the uterus is most liable to occur in connexion with parturition, viz., rapid labours on the one hand, and those attended with any difficulty in the extraction of the placenta on the other.

2nd. The necessity of immediately effecting the reposition of the organ. Should any difficulty arise, we may eithes have recourse to anæsthesia, or adopt the suggestion of Millot, of incising or dividing the cervix, so as to take off the constriction thereby exercised upon the fundus uteri.

3rd. In cases of chronic inversion, where serious symptoms arise, the possibility of effecting the reduction of the organ whilst the patient is in a state of anæsthesia.

4th. The futility of any local or constitutional treatment in arresting the hremorrhages which occur in these cases, and consequently the expediency of attempting the removal of the inverted portion of the uterus where reduction is impossible, and where these evince a tendency to recurrence.

5th. The dangers attending removal of the uterus both by ligature and excision being considerable, the propriety of attempting its extirpation by means of the electric cautery, aided by the apparatus I have proposed, or some modification of it.

Chester l'luce, IIyde Purk Gardens, July 1 Sö3.

\section{STATISTICAL ACCOLNT OF OBSTETRIC CASES, IN PRIVATE COUNTRY PRACTICE.}

By R. U. WEST, Esq.

TuE following statistics may perhaps interest some of the readers of this Journal. They give the history of about nineteen years of a private midwifery practice. In arranging my materials, I have found considerable pleasure in looking back upon a vast number of troubles, doubts, anxieties, and difficulties. I hope that they will not be looked upon as interesting to myself alone. Without further preface I subjoin my statement.

Number OF Cases.

2,083 labour produced 2,106 children, viz.: 1,060 boys and 1,046 girls. 364 cases were primiparous, or 1 in $5 \%$.

These 2,106 children were born with the following

PIREANTATIONS:

2,042 children presented some part of the head. Of these,

1,962 were expelled with the occiput under the arch of the pubes: In

3 cases where the head was so expelled, a hand was down by the side of the head.

3 were cases where the head was expelled with the occiput turived to the left acetabuluin.

59 were cases where the face or forehead came rou!nd to the symphysis pubis, or 1 in about $35 \frac{1}{2}$ : In 49 of these cases the head was so expelled: In 1 case where the head was so expelled, $a$ hand was down by the side of the head. In

1 case where the face had come round to the pubes, the pains forced the chin under the arch, and the face disengaged itself first. In

1 other case, feeling the nose arrested at the symphysis, I pulled at the orbits till the chin came under the arch, and the child was born with the face first.* In

- In both theso instances the labour was completed almost immediately - In both these instances the labour was conplcted alsions of the worst after the alteration of position. Ihey were form of cranial position into the easiest for me déguger la Boivin says: "Nous hyons vil an exewple din tête. Fu Heclard, protesse l'Art des Accouchemens, wu. i, page 230. 